\title{
Death Receptor 6 (DR6) Is Overexpressed in Astrocytomas
}

\author{
SARAH STEGMANN ${ }^{1}$, JAN-MICHAEL WERNER ${ }^{1,2}$, SASKIA KUHL ${ }^{1}$, GABRIELE RÖHN $^{1}$, \\ BORIS KRISCHEK $^{1}$, PANTELIS STAVRINOU ${ }^{1}$, ROLAND GOLDBRUNNER $^{1}$ and MARCO TIMMER ${ }^{1}$ \\ ${ }^{1}$ Laboratory for Neurooncology and Experimental Neurosurgery, Department of General Neurosurgery, \\ Center for Neurosurgery, Faculty of Medicine and University Hospital Cologne, \\ University of Cologne, Cologne, Germany; \\ ${ }^{2}$ Department of Neurology, University of Cologne, Cologne, Germany
}

\begin{abstract}
Background/Aim: Death receptor 6 (DR6) is a member of the tumor necrosis factor receptor superfamily. The expression of DR6 is elevated in different kinds of tumors including ovarian, breast cancer and adult sarcoma. In these tumors, the receptor may be handled as a new diagnostic and prognostic marker. Thus, we investigated the expression of DR6 in gliomas. Materials and Methods: Tumor and control tissues were extracted during neurosurgery and grouped according to the WHO classification. DR6 expression was investigated in low- and high-grade gliomas PCR $(n=70)$, immunofluorescence staining $(n=33)$ and western blot $(n=58)$. Additional analysis of TCGA-data was performed to assess the general alteration of DR6 in cancer and influence of IDH-mutation on DR6 expression in gliomas. Results: The expression of DR6 was significantly enhanced in gliomas $(p<0.05)$. It showed a trend towards rising expression with increasing malignancy of the tumor. Chemotherapy treatment could have an influence on DR6 expression. Conclusion: In our investigation, DR6 acts as a potential suitable diagnostic marker for gliomas.
\end{abstract}

With an incidence of $6 / 100,000$ per year, gliomas are the most common primary brain tumors. Despite intensive therapy including tumor resection and radio- and chemotherapy, the prognosis remains poor with a 5-yearsurvival-rate of $5.5 \%$ in glioblastomas $(1,2)$.

The death receptor 6 (DR6) or tumor-necrosis-factorreceptor 21 (TNFRSF21) is a member of the tumor necrosis factor receptor superfamily (TNFRSF) (3). DR6 is

Correspondence to: Dr. Marco Timmer, Department of General Neurosurgery, University Hospital Cologne, Kerpener Strasse 62, 50937 Cologne, Germany. Tel: +49 22147882802, Fax: +49 2214786257,e-mail: marco.timmer@uk-koeln.de

Key Words: Glioblastoma, astrocytoma, death receptor 6, DR6, TNFRSF21. physiologically expressed in different tissues including brain, pancreas and prostate (3). Like other death receptors, DR6 induces a caspase-dependent apoptosis (4-7). Additionally, DR6 activates the JNK- and NF-KB-pathway (3). A major physiological function is its involvement in brain development. It takes part in brain-angiogenesis and contributes to cell death and axonal pruning during development of proper neuronal connections $(5,8)$.

In cancer, the expression level of DR6 is increased in different tumor tissues including prostate, breast and ovarian cancer $(6,9)$. Within the tissues, the receptor seems to be mainly expressed by blood vessels $(10,11)$.

DR6 can be cleaved by matrix metalloproteinase 14 (MMP-14), which is why it can also be detected in the blood (12). In serum of breast-cancer patients, elevated DR6 is associated with higher grading of the tumor resembling higher activity of neovascularization (13). DR6 has also been used as diagnostic marker in ovarian cancer (14).

It appears, that DR6 has two main functions in tumor development and progression. It supports tumor angiogenesis via the NF-kB pathway and promotes cell migration in vitro, suggesting a role in the development of metastasis $(15,16)$. Both make DR6 a potential candidate for therapeutic approaches (17).

DR6 is expressed atypically in glioneuronal tumors (like gangliogliomas and dysembryoplastic neuroepithelial tumors) and an increased level of the receptor is associated with a longer period of epileptic seizure and a worse seizure outcome after surgery (7).

In gliomas, DR6 can be activated by TNF-related apoptosis-inducing ligands (TRAIL) and induce cancersensitive apoptosis - which is not the case in normal cerebral cortex glia cells (18). Its expression depending on the WHOgrade of gliomas as well as its qualification as diagnostic marker remains unclear. Therefore, this study investigated these open questions comparing low- and high-grade gliomas. As DR6 is involved in tumor apoptosis, the impact of chemotherapy on DR6 expression in glioblastomas was assessed. 
Table I. Summary of samples used for western blot concerning their number, histology and gender.

\begin{tabular}{lccccccc}
\hline & $\begin{array}{c}\text { Control } \\
\text { samples } \\
(\%)\end{array}$ & $\begin{array}{c}\text { Grade II } \\
\text { samples } \\
(\%)\end{array}$ & $\begin{array}{c}\text { Grade III } \\
\text { samples } \\
(\%)\end{array}$ & $\begin{array}{c}\text { Sec GBM } \\
\text { samples } \\
(\%)\end{array}$ & $\begin{array}{c}\text { Sec GBM + Chemo } \\
\text { samples } \\
(\%)\end{array}$ & $\begin{array}{c}\text { Prim GBM } \\
\text { samples } \\
(\%)\end{array}$ & $\begin{array}{c}\text { Prim GBM + Chemo } \\
\text { samples } \\
(\%)\end{array}$ \\
\hline $\begin{array}{l}\text { Number } \\
\text { Histology }\end{array}$ & 6 & 8 & 11 & 9 & 8 & 7 & 9 \\
$\quad \begin{array}{l}\text { Astrocytoma } \\
\text { Oligoastrocytoma }\end{array}$ & $0(0 \%)$ & $5(63 \%)$ & $7(64 \%)$ & $0(0 \%)$ & $0(0 \%)$ & $0(0 \%)$ & $0(0 \%)$ \\
$\quad \begin{array}{l}\text { Glioblastoma } \\
\text { Gender }\end{array}$ & $0(0 \%)$ & $0(0 \%)$ & $0(0 \%)$ & $9(100 \%)$ & $8(100 \%)$ & $0(0 \%)$ & $0(0 \%)$ \\
$\quad \begin{array}{l}\text { Male } \\
\text { Female }\end{array}$ & $4(71 \%)$ & $3(37 \%)$ & $9(82 \%)$ & $9(67 \%)$ & $5(63 \%)$ & $6(86 \%)$ & $7(100 \%)$ \\
\hline
\end{tabular}

\section{Materials and Methods}

Patients. Tissue samples were extracted during neurosurgery and directly frozen in liquid nitrogen. They were stored at $-80^{\circ} \mathrm{C}$ until further processing. Histology and grade were determined by two independent neuropathologists following WHO Classification 2007 (19). The study was approved by the local ethics committee (Application No. 03-170).

Patient groups were generated by their tumor grade resulting in the following: WHO grade II glioma, grade III glioma, secondary glioblastoma (sec GBM) without chemotherapy, secondary glioblastoma with chemotherapy, primary glioblastoma (without chemotherapy) and recurrent primary glioblastoma (prim GBM) with chemotherapy. As controls, distant peritumoral brain tissue was used which was histologically confirmed to be tumor free.

Quantitative real-time polymerase chain reaction. For quantitative real-time polymerase chain reaction (PCR), ten patients per group (70 samples in total) were measured. All samples were analysed in triplets. Extraction of RNA from frozen tumor tissue was performed using RNeasy Mini Kit (Qiagen, Germany). Quantity and purity were determined at 260 and $280 \mathrm{~nm}$. cDNA was generated using the QuantiTect Reverse Transcription Kit (Qiagen, Germany). PCR was performed with $5 \mu \mathrm{l}$ cDNA in a final volume of $20 \mu \mathrm{l}$ using RotorGene SYBR Green PCR Kit (Qiagen, Germany). In the Cycler RotorGene Q (Qiagen, Germany), samples were first heated to $95^{\circ} \mathrm{C}$ for five min. The two-step PCR was followed by $95^{\circ} \mathrm{C}$ for $5 \mathrm{sec}$ and $60^{\circ} \mathrm{C}$ for $10 \mathrm{sec}$ repeated 40 times. Succinate dehydrogenase complex, subunit A, flavoprotein variant (SDHA) functioned as housekeeping gene. For SDHA, the Quantitect Primer Assay (Qiagen, Germany) was used, DR6 primer was designed (Eurofins, Luxemburg, ForwardATTCCCCAGGCTGAGGACAAAC, Reverse-ACACACACACAC ACCCCAAAC).

Immunofluorescence. Cryotissues were sliced in $10 \mu \mathrm{m}$ sections and placed on object slides. Four samples per group were analysed (35 samples in total). Slides were circled with a pap-pen and washed with tris-buffered saline with $0.05 \%$ Tween 20 as detergent (TBST) three times. Samples were incubated in $5 \%$ goat-serum dissolved in Dulbecco's phosphate buffered saline (DPBS) for $2 \mathrm{~h}$ and washed again three times. Primary antibody DR6 (1:25; antibodies-online, Germany) was solved in $1 \%$ BSA and $0,1 \%$ Triton and each slice was incubated with $50 \mu \mathrm{l}$ of the solution at $4^{\circ} \mathrm{C}$ overnight. Sections were washed three times with TBST. As a secondary antibody Cy3 anti-rabbit (Jackson ImmunoResearch dianova; 1:500 in 1\% BSA) was used for $90 \mathrm{~min}$ at room temperature. Slices were washed five times with TBST and three times with distilled water. To prevent bleaching, samples were covered with anti-fade reagent ProLong (Thermo Fisher Scientific, USA) and coverslips. ProLong also contained DAPI (4',6-diamidino-2-phenylindole) to stain nuclei. Pictures were taken with fluorescence microscope (Axiovert 200M with Apotome, Carl Zeiss, Germany) with an excitation wavelength of $550 \mathrm{~nm}$ for $\mathrm{Cy} 3$ and $358 \mathrm{~nm}$ for DAPI. Immunoreaction was confirmed with positive-controls. Scale bares show $100 \mu \mathrm{m}$.

Western blot. To analyse the protein expression, 58 samples were measured three times (Table I). For protein isolation, samples were resuspended in $10 \mu \mathrm{l} / 1 \mathrm{mg}$ RIPA with protease inhibitor cocktail (Roche Diagnostics) and sonicated three times for $20 \mathrm{sec}$. They were incubated for one hour on ice. Solution was centrifuged (15 min, $15,000 \mathrm{rpm}, 4^{\circ} \mathrm{C}$ ) and supernatant was stored at $-80^{\circ} \mathrm{C}$. Bradford Assay (Bio-Rad) was performed to measure protein concentration. Standard curve was created with bovine serum albumin (BSA) in concentrations of $1 \mathrm{mg} / \mathrm{ml}, 5 \mathrm{mg} / \mathrm{ml}$ and $10 \mathrm{mg} / \mathrm{ml} .50 \mu \mathrm{g}$ total protein was aliquoted and mixed with LDS sample buffer and sample reducing agent (NuPAGE; Thermo Fisher Scientific, USA). Protein samples were denatured at $70^{\circ} \mathrm{C}$ for $10 \mathrm{~min}$ and separated via SDS PAGE (Sodiumdodecylsulfate - polyacrylamide gel electrophoresis) using prefabricated gels (NuPAGE $4 \%-12 \%$ Bis-Tris $1 \mathrm{~mm}$ gel) and the gel system of Thermo Fisher Scientific, USA, at 200V for 50 min. Protein standard Novex ${ }^{\circledR}$ (Thermo Fisher Scientific, USA) was used. After gel electrophoreses protein was blotted onto a nitrocellulose membrane using the blotting system of Thermo Fisher Scientific, USA, for $90 \mathrm{~min}$ at $300 \mathrm{~V}$. Membranes were blocked in $5 \%$ dry non-fat milk with $3 \%$ BSA dissolved in TBST for 90 min on a shaker at room temperature. Membranes were cut between 60 and $50 \mathrm{kDa}$. Primary antibody DR6 (1:500 in 5\% dry non-fat milk and $3 \%$ BSA; antibodies-online, Germany) and $\beta$-actin $(1: 10,000$ in TBST; Sigma Aldrich, USA) were incubated overnight at $4^{\circ} \mathrm{C}$ on a shaker. Membranes were washed three times with TBST. Samples were incubated with a secondary horseradish peroxidase-conjugated antibody $(1: 10,000)$ in TBST for $30 \mathrm{~min}$ on a shaker at room temperature. For DR6, an anti-rabbit-antibody (Cell Signaling Technology, USA) was used, $\beta$-actin needed an anti-mouse-antibody (Cell Signaling Technology, USA). Membranes were washed again 


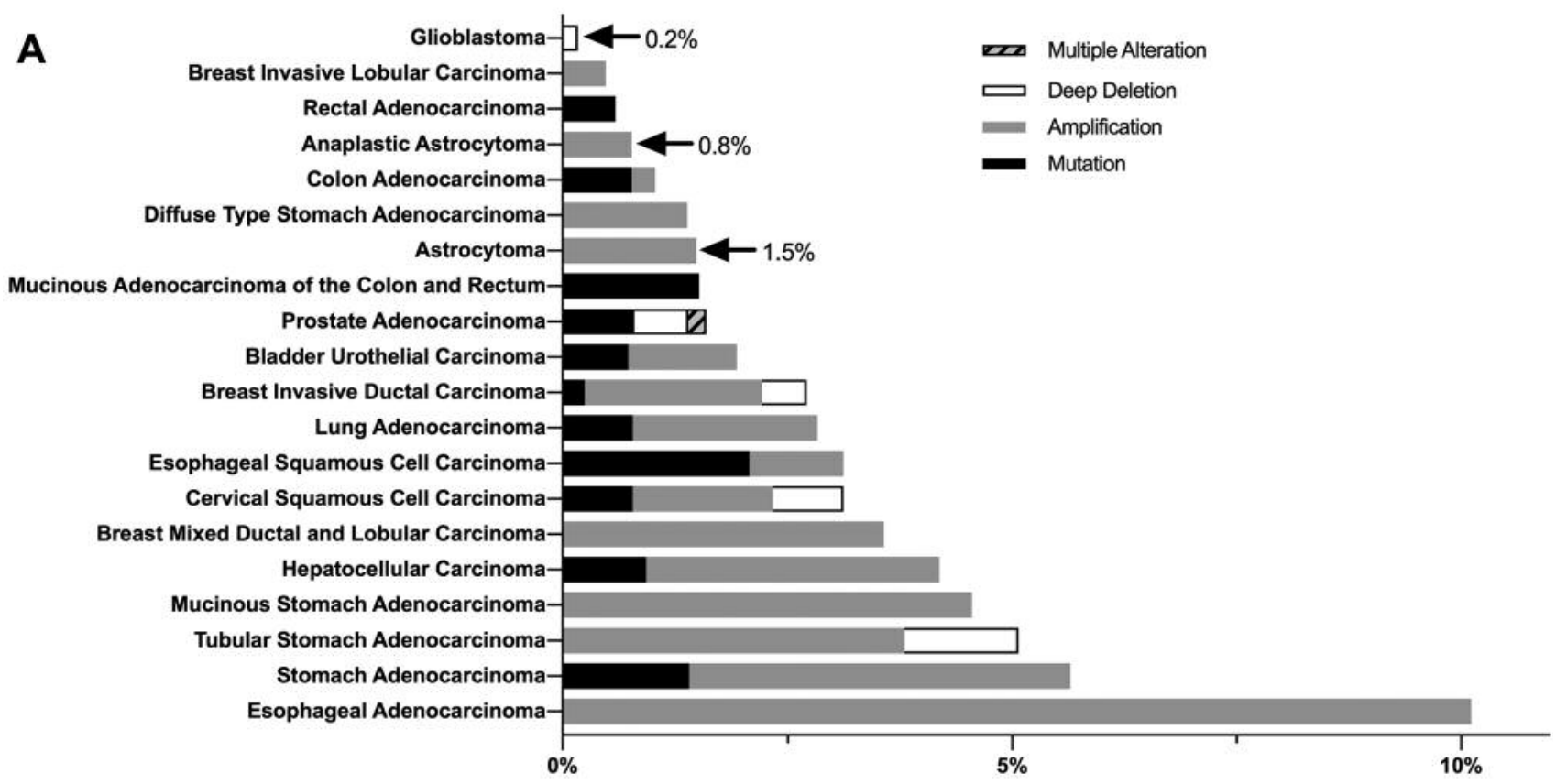

B

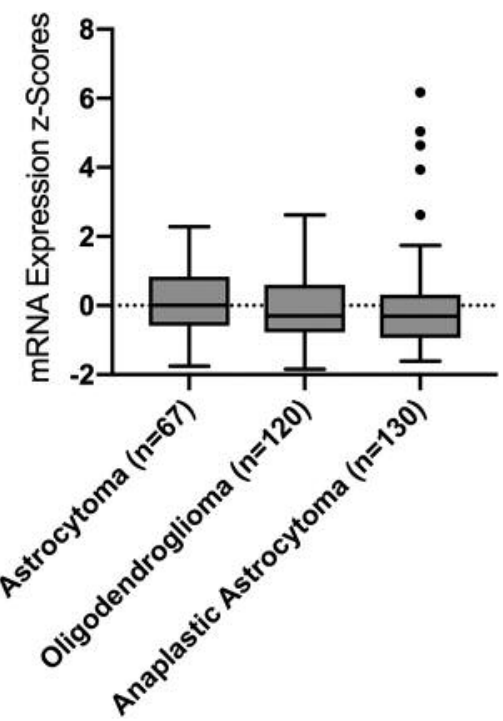

C

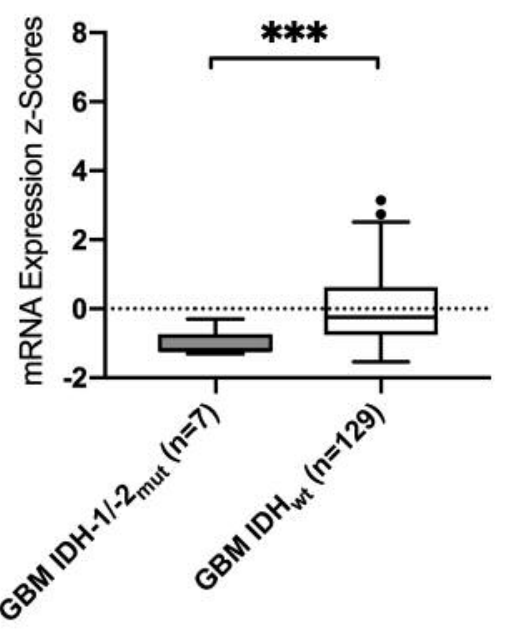

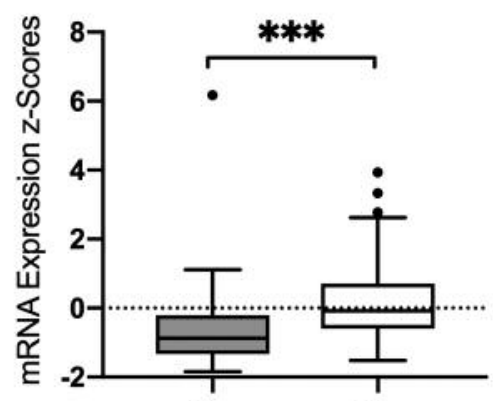

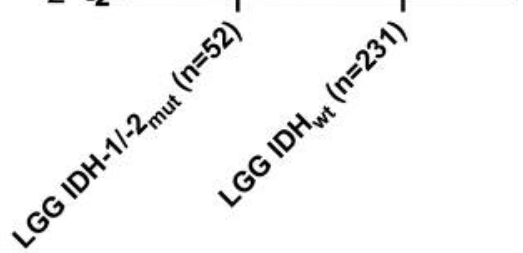

Figure 1. Analysis of TCGA-data focusing on (A) alterations of DR6 across various cancers including gliomas, (B) mRNA expression of DR6 in WHO grade II and III gliomas and (C) mRNA upregulation of DR6 in IDH-1/-2 mutated glioblastomas (GBM) and lower-grade-gliomas (LGG).

with TBST three times. Bands were visualized by using ECL-spray (advansta) and ChemiDox XRS + System, Bio-Rad. Density was measured with the Image Lab software (Biorad) and results were normalized using $\beta$-actin. Out of three results, the two that are closest in value to each other were used.

The Cancer Genomic Atlas (TCGA) data analysis. The results shown in Figure 1A-C are based upon data generated by the TCGA Research
Network: http://cancergenome.nih.gov/. Data access and analysis was performed using cBioPortal $(20,21)$. Selected cancer studies were Glioblastoma Multiforme (TCGA, Provisional) and Brain Lower Grade Glioma (TCGA, Provisional). The selected genomic profile was mRNA Expression z-Scores (RNA Seq V2 RSEM).

For the cross-cancer alteration analysis, data was limited to 10 cancer entities with the high incidence according to the GLOBOCAN 2018 estimates of cancer incidence and mortality 


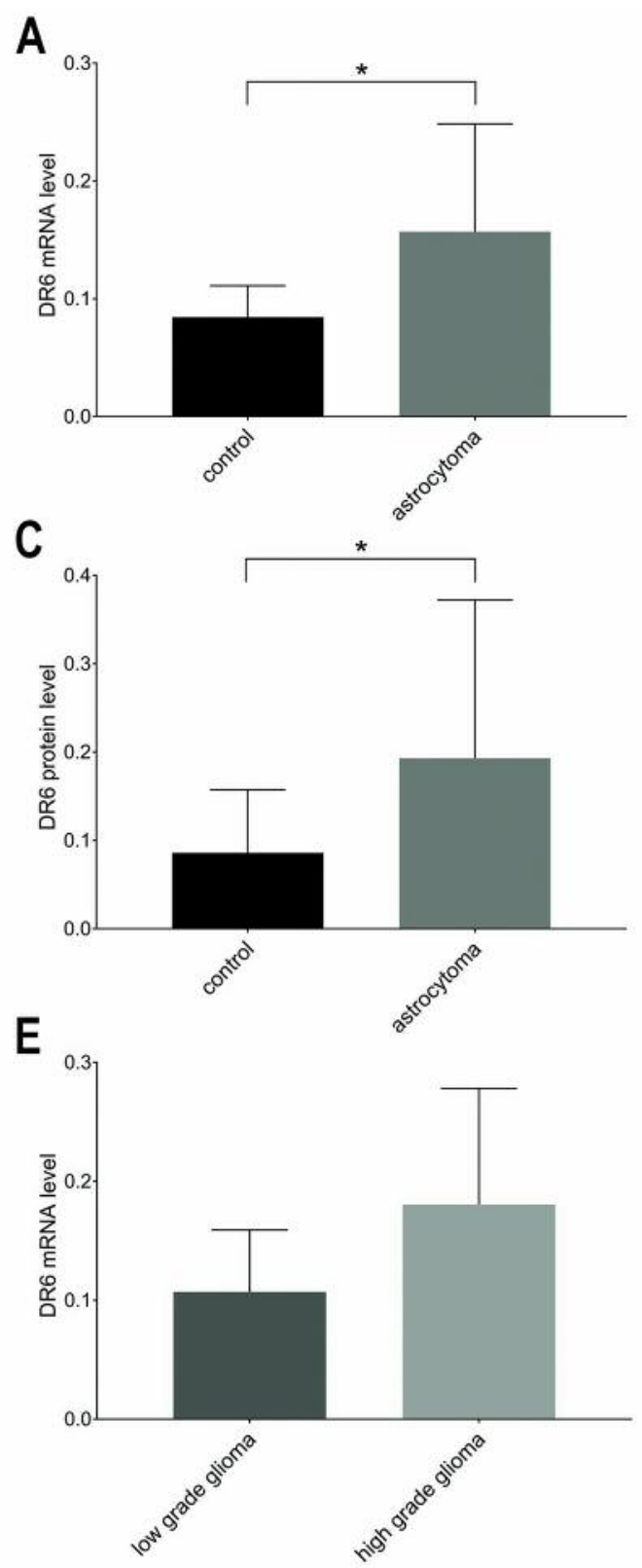

produced by the International Agency for Research on Cancer and glioblastoma and lower grade glioma (22). The selected datasets were: Bladder Urothelial Carcinoma; Colorectal Adenocarcinoma; Breast Invasive Carcinoma; Brain Lower Grade Glioma; Glioblastoma Multiforme; Cervical Squamous Cell Carcinoma and Endocervical Adenocarcinoma; Esophageal Carcinoma; Stomach Adenocarcinoma; Liver Hepatocellular Carcinoma; Lung Adenocarcinoma; Prostate Adenocarcinoma and Thyroid Carcinoma (all: TCGA, Provisional). Results were only displaid, if the alterations were above $0.1 \%$.
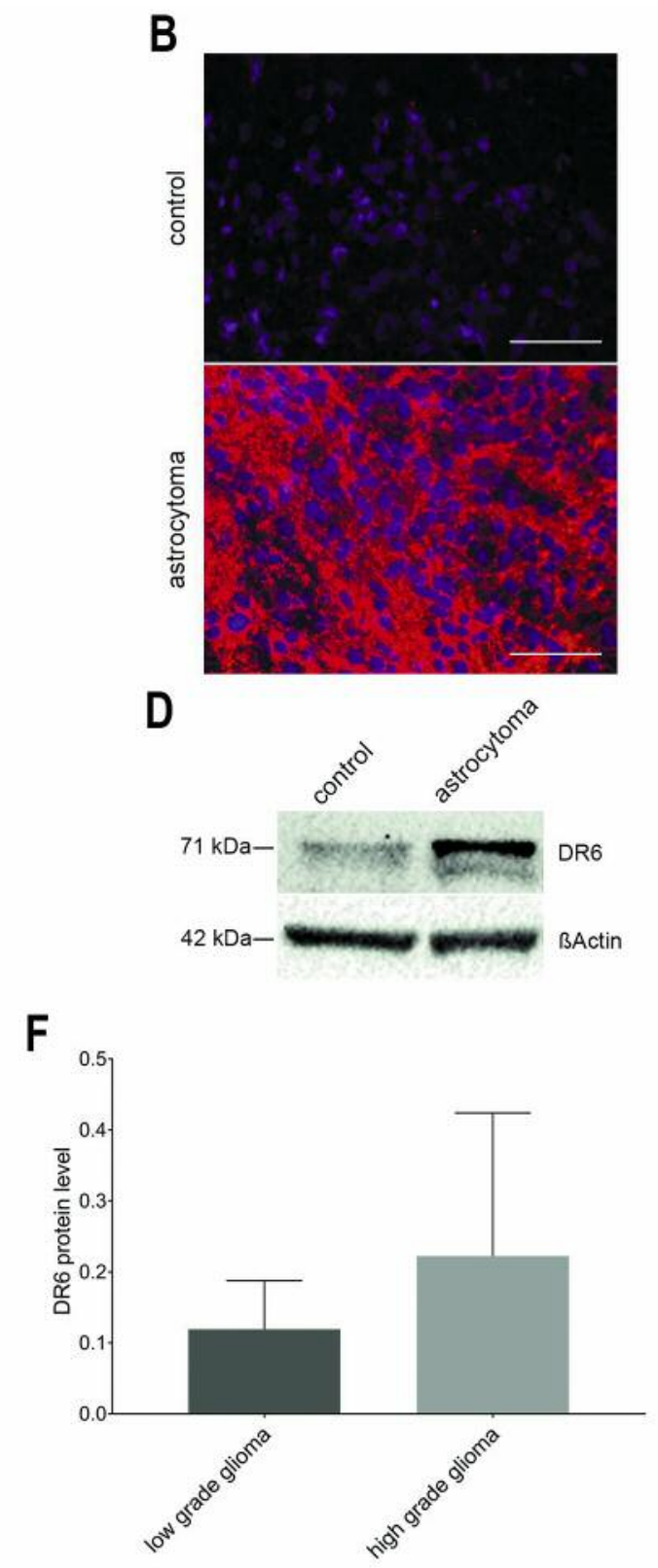

Figure 2. Continued

$\mathbf{F}$

Statistical analysis. Results were statistically analysed using Prism Graph Pad (version 7). Results lying outside the whiskers (1.5 times interquartile range) of boxplots were defined as outliers and sorted out. To verify if results were distributed normally, the Shapiro Wilk normality test was performed. Normally distributed data were analysed using ANOVA and Tukey's test or unpaired and paired $t$-test, while abnormal results with Kruskal-Wallis test and Mann-Whitney $U$-test. Significance was defined as $p \leq 0.05$. It was designated as stars, with $*$ $(p \leq 0.05), * *(p \leq 0.01)$ and $* * *(p \leq 0.001)$. Error bars mark the standard deviation. Adobe ${ }^{\circledR}$ Photoshop 2018 was used to create figures. 

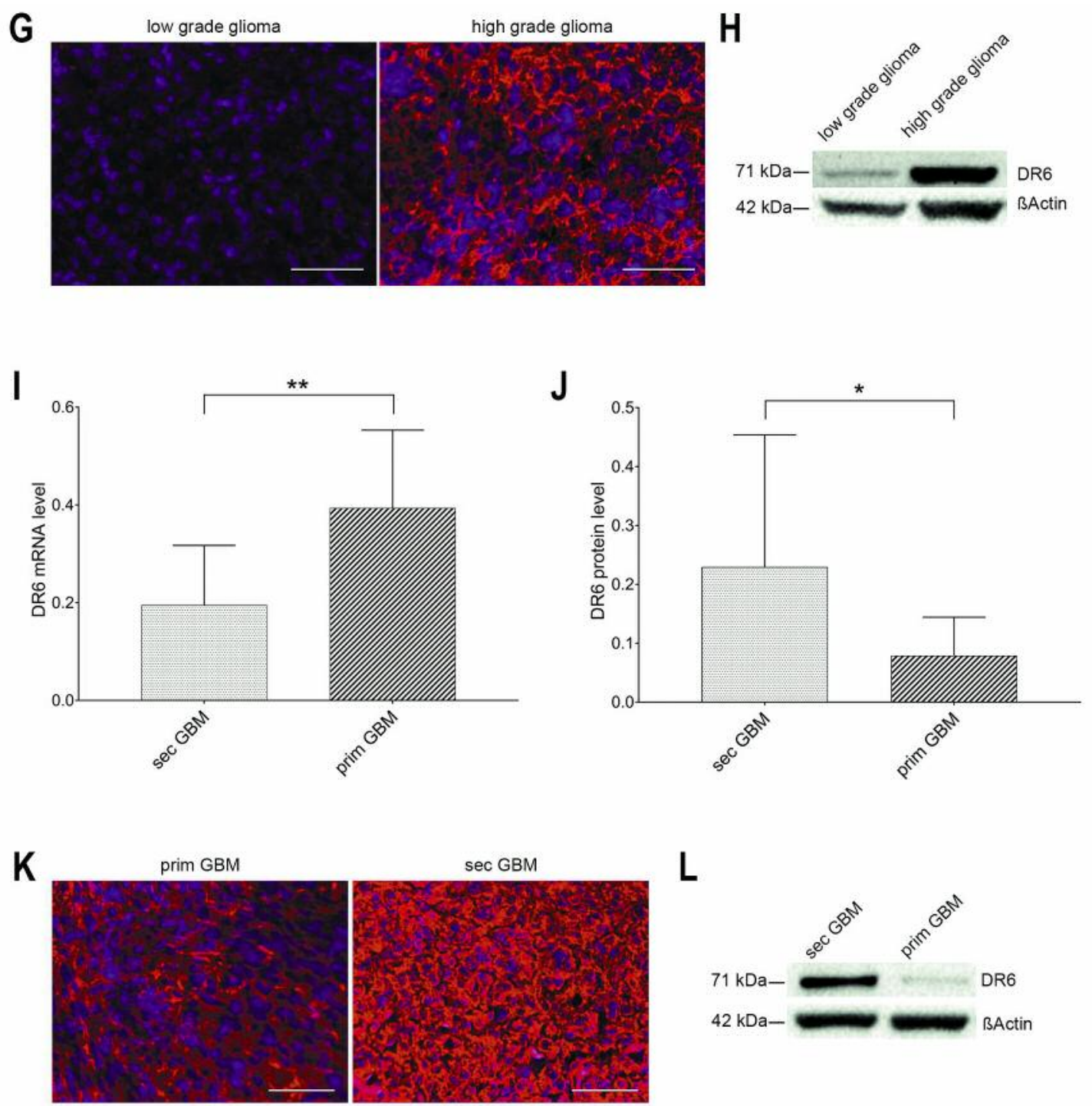

Figure 2. DR6 expression in astrocytomas compared to control tissue in (A) PCR, (B) immunofluorescence staining and (C-D) western blot. Differences in DR6 expression between low-grade glioma and high-grade glioma in $(E) P C R,(G)$ immunofluorescence staining and $(F, H)$ western blot. (I) PCR, $(K)$ immunofluorescence staining and $(J, L)$ western blot of secondary glioblastomas compared to primary glioblastomas.

\section{Results}

Analysis of DR6 expression using the TCGA data. Crosscancer analysis showed different gene alterations across the selected cancer studies with various alterations, but primarily amplifications. The analysis revealed low alterations of DR6 in low- and high-grade gliomas compared to the more frequent tumor entities (Figure 1a). In contrast to astrocytomas or anaplastic astrocytomas, glioblastomas did not show DR6 amplification, but deep deletion (although very rarely). With $1.5 \%$ DR6 amplification, astrocytomas showed the highest percentage of DR6 alteration in gliomas.
The comparison of mRNA expression within lower-grade gliomas showed no difference between astrocytomas, oligodendrogliomas and anaplastic astrocytomas (Figure 1b). In both low- and high-grade gliomas, the mRNA expression of DR6 was significantly higher in patients with IDH-1 or IDH-2 mutated gliomas ( $p<0.001$, Figure 1c).

DR6 expression in gliomas. Analysis of The Cancer Genomic Atlas (TCGA) revealed a genetic alteration of DR6 in some glioma patients. These patients had a longer progression free survival compared to persons without genetic modifications of DR6 (Figure 1A). On the mRNA 

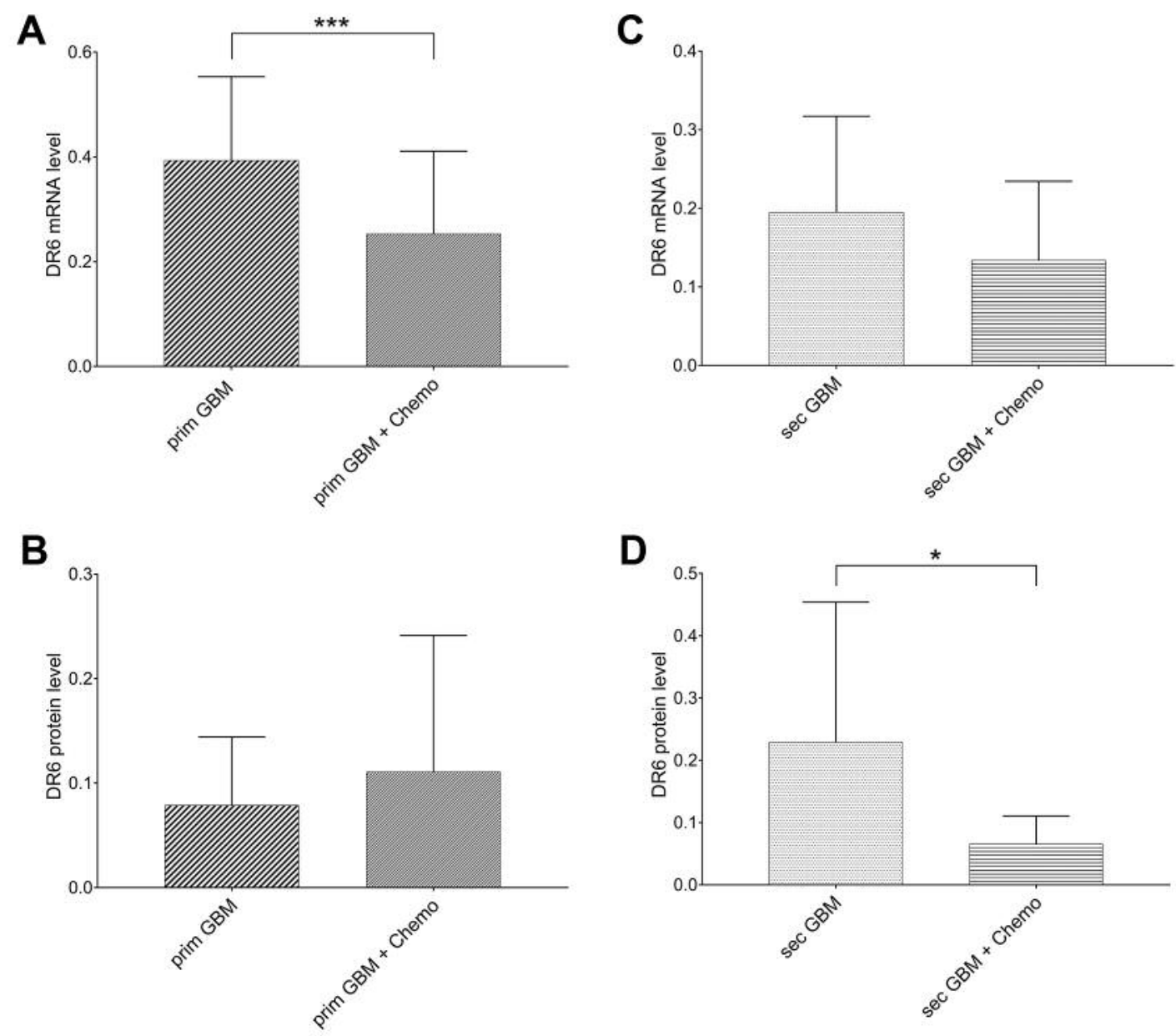

Figure 3. Comparison of glioblastomas and glioblastoma recurrences: (A) PCR and (B) western blot of primary gliolbastomas, (C) PCR and (D) western blot of secondary glioblastomas.

level, TCGA affirmed an upregulation of DR6 in $18 \%$ of gliomas making the receptor an interesting candidate for further investigations (Figure 1B).

We examined tumor tissue of gliomas compared to control tissue in PCR to better understand the expression of DR6 in this cancer. A total of 30 samples of tumor tissue from different tumor grades were measured and compared to 10 control samples. DR6 mRNA level was significantly upregulated in tumor tissue compared to the control group $(p<0.05$, Figure $2 \mathrm{~A})$. This difference could also be seen in immunofluorescence staining (Figure 2B). Analysing 6 controls and 28 tumor samples with western blot quantitatively confirmed the immunostaining with a $p$-value of $p=0.0374$ (Figure 2C-D).

DR6 expression rises with increasing malignancy. To investigate if there is any variation in DR6 expression depending on the tumor grade, we analyzed low-grade (grade
II) and high-grade gliomas (grade III and secondary glioblastoma). RNA level of DR6 shows a tendency towards higher expression in high grade glioma $(0.25 \pm 0.03 \mathrm{vs}$. $0.11 \pm 0.02$, Figure $2 \mathrm{E}$ ). On the protein level, this tendency could also be seen $(0.22 \pm 0.2 v s .0 .12 \pm 0.07$, Figure $2 \mathrm{~F}$ and $\mathrm{H})$. It is visualized in immunofluorescence staining (Figure 2G).

DR6 expression in glioblastoma. The expression of DR6 was analyzed in glioblastomas as well. Compared to secondary glioblastomas, the RNA expression was significantly enhanced in primary glioblastomas $(p<0.01$, Figure 2I). In general, primary glioblastomas showed the highest RNA expression of all tumor groups. On the protein level, secondary glioblastomas displayed the highest expression of DR6, significantly higher than in primary glioblastomas $(p<0.05)$, suggesting that posttranscriptional modifications of DR6 take place in these tumors (Figure 2J-L). We also investigated the differences between 
glioblastomas and glioblastoma recurrences. Concerning PCR, all samples of the group 'primary glioblastoma with chemotherapy' were recurrences of the 'primary glioblastoma' - patients. Looking at these paired groups, primary glioblastoma relapses showed a significantly decreased DR6 RNA expression ( $p<0.0001$, Figure 3A). Western blot did not show this decrease of DR6 (Figure 3B). PCR of secondary glioblastoma recurrences displayed a tendency towards a reduction of DR6 compared to secondary glioblastomas $(0.13 \pm 0.1$ vs. $0.2 \pm 0.12$; Figure $3 \mathrm{C})$. On the protein level, this decrease of DR6 expression in recurrences was significant $(p<0.05$; Figure 3D). As a common feature these patients share is their chemotherapy, a role of this treatment in DR6 reduction seems to exist.

\section{Discussion}

In this study, we confirm, that DR6 expression in glioma is different compared to normal brain tissue. This is in line with $\mathrm{He}$ and colleagues' suggestion in his receptome and proteome analysis of malignant glioma (18). The findings on up-regulated DR6-mRNA-expression in gliomas matches findings in other cancer types $(6,9)$. How these tumor cells can survive with this high amount of DR6, even though it is a death receptor causing caspase-dependent apoptosis, is not fully understood yet. Kasof and colleagues explained this phenomenon by the higher expression of the anti-apoptotic protein Bcl-xL in prostate cancer cell lines. BCL-xL is mediated by the NF-kB pathway and inhibits DR6-mediated apoptosis. As BCL-xL is also upregulated in gliomas and is known to inhibit apoptosis in this tumor (23), it might have the same effect on DR6 as in prostate cancer cells.

In ovarian carcinoma, DR6 expression in tumor tissue rises with increasing malignancy of the tumor (9). BilecovaRabajdova and colleagues were able to show, that in serum of breast carcinoma patients the expression of DR6 increases with every tumor grade, starting with the lowest level in grade I breast carcinoma and the highest level in grade III (13). We showed a tendency of rising expression between low- and high-grade glioma that corresponded to these findings. To verify, whether this effect can also be seen between grade II glioma, grade III and glioblastoma and if this tendency can be confirmed on a significant level, further investigations need to be performed. The data obtained from the TCGA showed a significantly higher mRNA expression of DR6 in IDH-mutated gliomas. As IDH-wildtype gliomas are predominantly glioblastomas, IDH-mutation status has to be taken into account when comparing DR6 expression in further studies.

We demonstrated, that protein levels and receptor expression of DR6 was higher in secondary glioblastomas compared to primary glioblastomas. On the other hand, the mRNA data showed the opposite. These initially controversial results may be owed to the different patient groups' composition of the IDH mutation. Changes of DR6 could be interesting, as a reduction of DR6 level in serum correlates with therapeutic success in sarcomas (24).

We were recently able to demonstrate, that FAS-L a TNFR-ligand could be used as a prognostic marker in primary low-grade gliomas (25). To ascertain, if DR6 could be handled as a prognostic marker in gliomas, progression free- and survival analysis are necessary and IDH-mutation analysis is needed. In general, DR6 blood-levels could be of interest, supporting the results we have found in tumor tissue and proving its suitability as a diagnostic or prognostic marker.

\section{Authors' Contributions}

SS, experimental work, statistics, manuscript writing; JMW, TCGA data, idea; SK, experimental work; GR, PCR; BK, comments on manuscript; PS, comments on manuscript; RG, comments on manuscript; MT, statistics, supervision, manuscript writing, idea.

\section{Acknowledgements}

Sarah Stegmann was supported by a fellowship of 'Köln Fortune'. The grant was given to Marco Timmer.

\section{References}

1 Weller M, van den Bent M, Tonn JC, Stupp R, Preusser M, Cohen-Jonathan-Moyal E, Henriksson R, Rhun EL, Balana C, Chinot O, Bendszus M, Reijneveld JC, Dhermain F, French P, Marosi C, Watts C, Oberg I, Pilkington G, Baumert BG, Taphoorn MJB, Hegi M, Westphal M, Reifenberger G, Soffietti R, Wick W, and European Association for Neuro-Oncology Task Force on G: European Association for Neuro-Oncology (EANO) guideline on the diagnosis and treatment of adult astrocytic and oligodendroglial gliomas. Lancet Oncol 18(6): e315-e329, 2017. PMID: 28483413. DOI: 10.1016/S1470-2045(17)30194-8

2 Ostrom QT, Gittleman H, Fulop J, Liu M, Blanda R, Kromer C, Wolinsky Y, Kruchko C and Barnholtz-Sloan JS: CBTRUS Statistical Report: Primary Brain and Central Nervous System Tumors Diagnosed in the United States in 2008-2012. Neuro Oncol 17(Suppl 4): iv1-iv62, 2015. PMID: 26511214. DOI: 10.1093/neuonc/nov189

3 Pan G, Bauer JH, Haridas V, Wang S, Liu D, Yu G, Vincenz C, Aggarwal BB, Ni J and Dixit VM: Identification and functional characterization of DR6, a novel death domain-containing TNF receptor. FEBS Lett 431: 351-356, 1998. PMID: 9714541

4 Mi S, Lee X, Hu Y, Ji B, Shao Z, Yang W, Huang G, Walus L, Rhodes K, Gong BJ, Miller RH and Pepinsky RB: Death receptor 6 negatively regulates oligodendrocyte survival, maturation and myelination. Nat Med 17: 816-821, 2011. PMID: 21725297. DOI: $10.1038 / \mathrm{nm} .2373$

5 Nikolaev A, McLaughlin T, O'Leary DD and Tessier-Lavigne M: APP binds DR6 to trigger axon pruning and neuron death via distinct caspases. Nature 457: 981-989, 2009. PMID: 19225519. DOI: $10.1038 /$ nature 07767 
6 Kasof GM, Lu JJ, Liu D, Speer B, Mongan KN, Gomes BC and Lorenzi MV: Tumor necrosis factor-alpha induces the expression of DR6, a member of the TNF receptor family, through activation of NF-kappaB. Oncogene 20: 7965-7975, 2001. PMID: 11753679. DOI: 10.1038/sj.onc.1204985

7 Prabowo AS, Iyer AM, Veersema TJ, Anink JJ, Schouten-van Meeteren AY, Spliet WG, van Rijen PC, Ferrier CH, Thom M and Aronica E: Expression of neurodegenerative disease-related proteins and caspase- 3 in glioneuronal tumours. Neuropathol Appl Neurobiol 41: e1-e15, 2015. PMID: 24750067

8 Tam SJ, Richmond DL, Kaminker JS, Modrusan Z, MartinMcNulty B, Cao TC, Weimer RM, Carano RA, van Bruggen N and Watts RJ: Death receptors DR6 and TROY regulate brain vascular development. Dev Cell 22: 403-417, 2012. PMID: 22340501. DOI: 10.1016/j.devcel.2011.11.018

9 McNeal S, Bitterman P, Bahr JM, Edassery SL, Abramowicz JS, Basu S and Barua A: Association of Immunosuppression with DR6 Expression during the Development and Progression of Spontaneous Ovarian Cancer in Laying Hen Model. J Immunol Res 2016: 6729379, 2016. PMID: 27579331

10 Buckanovich RJ, Sasaroli D, O’Brien-Jenkins A, Botbyl J, Hammond R, Katsaros D, Sandaltzopoulos R, Liotta LA, Gimotty PA and Coukos G: Tumor vascular proteins as biomarkers in ovarian cancer. J Clin Oncol 25: 852-861, 2007. PMID: 17327606. DOI: 10.1200/JCO.2006.08.8583

11 Barua A, Yellapa A, Bahr JM, Abramowicz JS, Edassery SL, Basu S, Rotmensch J and Bitterman P: Expression of death receptor 6 by ovarian tumors in laying hens, a preclinical model of spontaneous ovarian cancer. Transl Oncol 5: 260-268, 2012. PMID: 22937178

12 Tam EM, Morrison CJ, Wu YI, Stack MS and Overall CM: Membrane protease proteomics: Isotope-coded affinity tag MS identification of undescribed MT1-matrix metalloproteinase substrates. Proc Natl Acad Sci USA 101: 6917-6922, 2004. PMID: 15118097. DOI: 10.1073/pnas.0305862101

13 Bilecova-Rabajdova M, Urban P, Gregova K, Varga J, Fialkovicova V, Kruzliak P and Marekova M: Breast carcinoma progression and tumour vascular markers related to apoptotic mechanisms. Dis Markers 2014: 156034, 2014. PMID: 24696529

14 Sasaroli D, Gimotty PA, Pathak HB, Hammond R, Kougioumtzidou E, Katsaros D, Buckanovich R, Devarajan K, Sandaltzopoulos R, Godwin AK, Scholler N and Coukos G: Novel surface targets and serum biomarkers from the ovarian cancer vasculature. Cancer Biol Ther 12: 169-180, 2011. PMID: 21617380

15 Shi B, Bao J, Liu Y and Shi J: Death receptor 6 promotes ovarian cancer cell migration through KIF11. FEBS Open Bio 8: 1497-1507, 2018. PMID: 30186750. DOI: 10.1002/22115463.12492

16 Strilic B, Yang L, Albarran-Juarez J, Wachsmuth L, Han K, Muller UC, Pasparakis M and Offermanns S: Tumour-cellinduced endothelial cell necroptosis via death receptor 6 promotes metastasis. Nature 536: 215-218, 2016. PMID: 27487218. DOI: $10.1038 /$ nature19076
17 Yang X, Shi B, Li L, Xu Z, Ge Y, Shi J, Liu Y and Zheng D: Death receptor 6 (DR6) is required for mouse B16 tumor angiogenesis via the NF-kappaB, P38 MAPK and STAT3 pathways. Oncogenesis 5: e206, 2016. PMID: 26950598. DOI: 10.1038/oncsis.2016.9

18 He Y, Yu Z, Ge D, Wang-Sattler R, Thiesen HJ, Xie L and Li Y: Cell type specificity of signaling: view from membrane receptors distribution and their downstream transduction networks. Protein Cell 3: 701-713, 2012. PMID: 22802048. DOI: 10.1007/s13238012-2049-y

19 Louis DN, Ohgaki H, Wiestler OD, Cavenee WK, Burger PC, Jouvet A, Scheithauer BW and Kleihues P: The 2007 WHO classification of tumours of the central nervous system. Acta Neuropathol 114: 97-109, 2007. PMID: 17618441. DOI: 10.1007/ s00401-007-0243-4

20 Gao J, Aksoy BA, Dogrusoz U, Dresdner G, Gross B, Sumer SO, Sun Y, Jacobsen A, Sinha R, Larsson E, Cerami E, Sander $\mathrm{C}$ and Schultz N: Integrative analysis of complex cancer genomics and clinical profiles using the cBioPortal. Sci Signal 6: pl1, 2013. PMID: 23550210. DOI: 10.1126/scisignal.2004088

21 Cerami E, Gao J, Dogrusoz U, Gross BE, Sumer SO, Aksoy BA, Jacobsen A, Byrne CJ, Heuer ML, Larsson E, Antipin Y, Reva B, Goldberg AP, Sander C and Schultz N: The cBio cancer genomics portal: an open platform for exploring multidimensional cancer genomics data. Cancer Discov 2: 401-404, 2012. PMID: 22588877. DOI: 10.1158/2159-8290.CD-12-0095

22 Bray F, Ferlay J, Soerjomataram I, Siegel RL, Torre LA and Jemal A: Global cancer statistics 2018: GLOBOCAN estimates of incidence and mortality worldwide for 36 cancers in 185 countries. CA Cancer J Clin 68: 394-424, 2018. PMID: 30207593. DOI: $10.3322 /$ caac. 21492

23 Weiler M, Bahr O, Hohlweg U, Naumann U, Rieger J, Huang H, Tabatabai G, Krell HW, Ohgaki H, Weller M and Wick W: BCL-xL: time-dependent dissociation between modulation of apoptosis and invasiveness in human malignant glioma cells. Cell Death Differ 13: 1156-1169, 2006. PMID: 16254573. DOI: 10.1038/sj.cdd. 4401786

24 Yang K, Mooney C, Spahlinger G, Schuetze S, Arias-Pulido H, Verschraegen C, Gimotty P and Buckanovich RJ: DR6 as a diagnostic and predictive biomarker in adult sarcoma. PLoS One 7: e36525, 2012. PMID: 22567163. DOI: 10.1371/journal.pone. 0036525

25 Werner JM, Kuhl S, Stavrinou P, Rohn G, Krischek B, Blau T, Goldbrunner R and Timmer M: Expression of FAS-L differs from primary to relapsed low-grade gliomas and predicts progression-free survival. Anticancer Res 37: 6639-6648, 2017. PMID: 29187439. DOI: 10.21873/anticanres.12121
Received April 9, 2019

Revised April 17, 2019 Accepted April 18, 2019 